\title{
Receptor-mediated net breakdown of phosphatidylinositol 4,5-bisphosphate in parotid acinar cells
}

\author{
Stuart J. WEISS, ${ }^{*}$ Jerry S. McKINNEY and James W. PUTNEY, Jr.† \\ Department of Pharmacology, Medical College of Virginia, Virginia Commonwealth University, \\ Richmond, VA 23298, U.S.A.
}

(Received 29 March 1982/Accepted 4 June 1982)

\begin{abstract}
The metabolism of phosphatidylinositol 4-phosphate (PtdIns4P) and phosphatidylinositol 4,5-bisphosphate [PtdIns $(4,5) P_{2}$ ] in rat parotid acinar cells was investigated, particularly with regard to the effects of receptor-active agonists. Stimulation of cholinergic-muscarinic receptors with methacholine provoked a rapid disappearance of $40-50 \%$ of $\left[{ }^{32} \mathrm{P}\right] \mathrm{Ptd} \operatorname{Ins}(4,5) P_{2}$, but had no effect on PtdIns4P. Adrenaline, acting on $\alpha$-adrenoceptors, and Substance $P$ also stimulated net loss of $\operatorname{PtdIns}(4,5) P_{2}$. The $\beta$-adrenoceptor agonist, isoprenaline, and the $\mathrm{Ca}^{2+}$ ionophore, ionomycin, failed to affect labelled PtdIns $(4,5) P_{2}$ or PtdIns4P. By chelation of extracellular $\mathrm{Ca}^{2+}$ with excess EGTA, and by an experimental protocol that eliminates cellular $\mathrm{Ca}^{2+}$ release, it was demonstrated that the agonist-induced decrease in $\operatorname{PtdIns}(4,5) P_{2}$ is independent of both $\mathrm{Ca}^{2+}$ influx and $\mathrm{Ca}^{2+}$ release. These results may suggest that net $\operatorname{PtdIns}(4,5) P_{2}$ breakdown is an early event in the stimulus-response pathway of the parotid acinar cell and could be directly involved in the mechanism of agonist-induced $\mathrm{Ca}^{2+}$ release from the plasma membrane.
\end{abstract}

Much of the current interest in phosphoinositide metabolism centres around a hypothesis offered by Michell (1975) suggesting that phospholipase Cmediated breakdown of PtdIns may be involved in the mechanism by which receptor activation is coupled to $\mathrm{Ca}^{2+}$-mobilization (Michell, 1979; Berridge, 1980; Putney, 1981). The evidence for this idea stems largely from the striking (and apparently exclusive) association of enhanced PtdIns breakdown with receptors that act by mobilizing $\mathrm{Ca}^{2+}$, together with the demonstration that receptor stimulation of PtdIns breakdown is itself apparently not a $\mathrm{Ca}^{2+}$-mediated event. The latter point derives from the experimental findings that phospholipase C-mediated PtdIns breakdown is minimally (or not at all) inhibited by removal of extracellular $\mathrm{Ca}^{2+}$, and is not activated by $\mathrm{Ca}^{2+}$ ionophores (there are exceptions; Cockroft et al., $1980 a, b$; Fisher \& Agranoff, 1980).

In addition to the breakdown of PtdIns, in some

Abbreviations used: PtdIns, phosphatidylinositol; PtdIns4P, phosphatidylinositol 4-phosphate; PtdIns$(4,5) P_{2}$, phosphatidylinositol 4,5-bisphosphate.

* Present address: Laboratory of Biochemical Pharmacology, National Institute of Arthritis, Metabolic and Digestive Diseases, National Institutes of Health, Bethesda, MD 20205, U.S.A.

$\dagger$ To whom reprint requests should be addressed. systems it has been demonstrated that phosphorylated derivatives of PtdIns, the polyphosphoinositides, are also broken down in response to receptor activation (Abdel-Latif et al., 1977). This effect, however, has been shown to be $\mathrm{Ca}^{2+}$-dependent and mimicked by $\mathrm{Ca}^{2+}$-ionophores (Akhtar \& AbdelLatif, 1978), leading to the suggestion that polyphosphoinositide breakdown is probably not involved in the mechanism of $\mathrm{Ca}^{2+}$-mobilization but rather may be involved in the mechanism(s) by which the cellular responses to $\mathrm{Ca}^{2+}$ are expressed (Akhtar \& Abdel-Latif, 1978; Putney, 1978).

In a recent study with hepatocytes, Kirk et al. (1981) examined the effects of vasopressin, a $\mathrm{Ca}^{2+}$ mobilizing hormone, on polyphosphoinositide metabolism. These investigators found that vasopressin caused a rapid breakdown of the polyphosphoinositides; the effect was only partially inhibited by $\mathrm{Ca}^{2+}$ omission. Additionally, the $\mathrm{Ca}^{2+}$-ionophore A23187 did not activate polyphosphoinositide breakdown. Kirk et al. (1981) suggest that polyphosphoinositide breakdown may be an early event in hepatocyte activation, perhaps preceding PtdIns breakdown.

In the present study we have examined the effects of agonists on the ${ }^{32} \mathrm{P}$-labelled polyphosphoinositides, PtdIns4P and PtdIns $(4,5) P_{2}$ in the rat parotid acinar cell. The results show that in the 
parotid gland, net PtdIns $(4,5) P_{2}$ breakdown occurs, is a $\mathrm{Ca}^{2+}$-independent response to receptor activation and could therefore play some role in the mechanism of $\mathrm{Ca}^{2+}$-mobilization.

\section{Experimental}

Parotid glands were removed from anaesthetized (sodium pentobarbitone) male Sprague-Dawley rats (140-200 g) and dispersed acinar cells were prepared as previously described (Putney et al., 1978). The cells were suspended at a concentration of $1-2 \mathrm{mg}$ of protein $/ \mathrm{ml}$ in a Ringer medium of the following composition (mM); $\mathrm{NaCl}, 120 ; \mathrm{KCl}, 5.0 ; \mathrm{MgCl}_{2}$, 1.2: $\mathrm{CaCl}_{2}, 1.0 ;$ Tris, 20 ; sodium $\beta$-hydroxybutyrate, 5.0; and $0.5 \%$ bovine serum albumin. The media were titrated with $\mathrm{HCl}$ (about $10 \mathrm{mM}^{\circ}$ inal $\mathrm{Cl}^{-}$concentration) to a $\mathrm{pH}$ of 7.4 at $37^{\circ} \mathrm{C}$. The gas phase was $100 \% \mathrm{O}_{2}$.

Cells were equilibrated with the above medium for $20 \mathrm{~min}$, at which time $10 \mu \mathrm{M}-\left[{ }^{32} \mathrm{P}\right] \mathrm{P}_{\mathrm{i}}$ was added as the neutral sodium salt. The specific radioactivity of the ${ }^{32} \mathrm{P} \mid \mathrm{P}_{\mathrm{i}}$ was adjusted so that the $10 \mu \mathrm{M}$ concentration provided a radioactivity concentration of about $5 \mu \mathrm{Ci} / \mathrm{ml}$. At various times thereafter drugs were added to the media and portions of the cell suspension were taken for analysis. The portions $(0.6 \mathrm{ml})$ were rapidly homogenized in $2.25 \mathrm{ml}$ of chloroform/methanol $(1: 2, \mathrm{v} / \mathrm{v})+2.0 \mu \mathrm{l}$ of $6 \mathrm{M}-\mathrm{HCl}$ and the phospholipids were extracted by the method of Bligh \& Dyer (1959) as modified by Lapetina \& Michell (1972). The PtdIns4P and PtdIns $(4,5) P_{2}$ were separated from other radioactive phospholipids by t.l.c. in one dimension as described by Schacht (1978) and visually detected by autoradiography. The method employs $10 \mathrm{~cm}$ plates coated with $0.25 \mathrm{~mm}$ silica gel 60 (EM reagents) and a solvent system of chloroform/methanol/aq. $\mathrm{NH}_{3} /$ water (90:90:7:20, by vol.). The spots described by Schacht (1978) as being PtdIns4P and PtdIns $(4,5) P_{2}$ co-migrated with appropriate standards, and remained as a single spot in a few experiments when chromatograms were developed in a second dimension in chloroform/methanol/acetic acid/water (120:46:19:3, by vol.). Additionally, in one experiment (described in the Results section) in which a rat was injected with ${ }^{3} \mathrm{H}$ linositol, as expected, most of the radioactivity migrated with PtdIns with lesser amounts of radioactivity in the spots attributed to PtdIns4 $P$ and PtdIns $(4,5) P_{2}$.

The areas corresponding to PtdIns $4 P$ and PtdIns(4,5) $P_{2}$ were scraped into scintillation vials, $5 \mathrm{ml}$ of water was added and radioactivity was quantified from Cerenkov radiation in a liquid-scintillation counter. As there was insufficient material to measure PtdIns4 $P$ and PtdIns $(4,5) P_{2}$ chemically. the extent of labelling is generally expressed as a percentage of some control value, usually just before drug additions. Experiments were generally repeated three to four times and means \pm S.E.M. are given. All observed effects of drugs etc. are based on demonstrated statistical significance $(P<0.05)$, usually by analysis of variance.

The enzymes used for cell dispersion, acetyl- $\beta$ methylcholine, adrenaline, propranolol, isoprenaline, atropin and authentic PtdIns4P and PtdIns $(4,5) P_{2}$ were purchased from Sigma Chemical Co., St. Louis, Missouri, U.S.A. Substance P was purchased from Peninsula Laboratories, San Carlos, CA, U.S.A. Ionomycin was kindly donated by Mr. S. J. Lucania of the Squibb Institute for Medical Research, Princeton, NJ, U.S.A. $\left[{ }^{32} \mathrm{P}\right] \mathrm{P}_{1}$ and $\left[{ }^{3} \mathrm{H}\right]-$ inositol were purchased from New England Nuclear, Boston, MA, U.S.A.

\section{Results}

The time course of accumulation of $\left[{ }^{32} \mathrm{P}\right] \mathrm{P}_{\mathrm{i}}$ into PtdIns4P and Ptdins $(4,5) P_{2}$ of rat parotid glands is summarized in Fig. 1. Both PtdIns $4 P$ and PtdIns$(4,5) P_{2}$ are rapidly labelled and with apparently identical kinetics. This may indicate that some step before the phosphorylation of the lipids, such as ${ }^{32} \mathrm{P} \mid \mathrm{P}_{\mathrm{i}}$ uptake or ATP labelling, may be rate-limiting. Both compounds appear to be labelled to near steady-state by $90 \mathrm{~min}$, with a half-time of $19 \mathrm{~min}$.

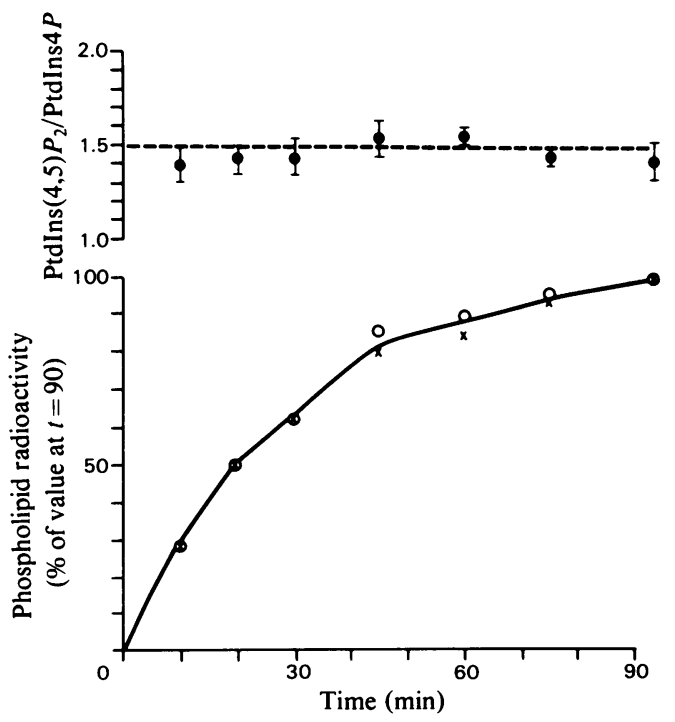

Fig. 1. Time course of incorporation of $\left[{ }^{32} P \mid P_{i}\right.$ in polyphosphoinositides in rat parotid acinar cells

Data from four experiments were expressed as percentages of the $90 \mathrm{~min}$ value. Values are means \pm S.E.M. for PtdIns $(4,5) P_{2} / P \operatorname{tdIns} 4 P$ ratio. $O$, PtdIns $(4,5) P_{2} ; \times$, PtdIns $4 P$. 
When the cholinergic-muscarinic agonist, methacholine, was added to the suspension of cells, rapid $\left(t_{1}<1 \mathrm{~min}\right)$ disappearance of about $45 \%$ of labelled PtdIns(4,5) $P_{2}$, but not PtdIns4P, occurred (Fig. 2). The small increase in PtdIns $4 P$ at $1 \mathrm{~min}$ was also seen in unstimulated controls (not shown) from which these data did not differ significantly. This may result from a small sampling artifact as it was generally seen in the PtdIns $(4,5) P_{2}$ controls as well (Fig. 3, for example). The apparent time course for loss of radioactivity from PtdIns $(4,5) P_{2}$ was identical whether cells were pre-incubated with $\left[{ }^{32} \mathbf{P}\right] \mathbf{P}_{\mathbf{i}}$ for 30 or $60 \mathrm{~min}$. This suggests that $\left[{ }^{32} \mathrm{P}\right] \mathrm{P}_{\mathrm{i}}$ uniformly labels a homogeneous pool of PtdIns $(4,5) P_{2}$ (not necessarily total cellular $\left.\operatorname{PtdIns}(4,5) P_{2}\right)$, and that the percentage change in radioactive $\operatorname{PtdIns}(4,5) P_{2}$ probably reflects similar net changes in mass for the specific pool of PtdIns $(4,5) P_{2}$ labelled under these conditions. For the remaining experiments in vitro, the period of pre-incubation with $\left[{ }^{32} \mathrm{P}\right] \mathrm{P}_{\mathrm{i}}$ was 60 min.

Agents acting on the three known $\mathrm{Ca}^{2+}$-mobilizing receptors in the parotid were compared with respect to their abilities to provoke loss of radioactive $P$ tdIns $(4,5) P_{2}$; the results are summarized in Fig. 3. Adrenaline was used together with $10 \mu \mathrm{M}$ -

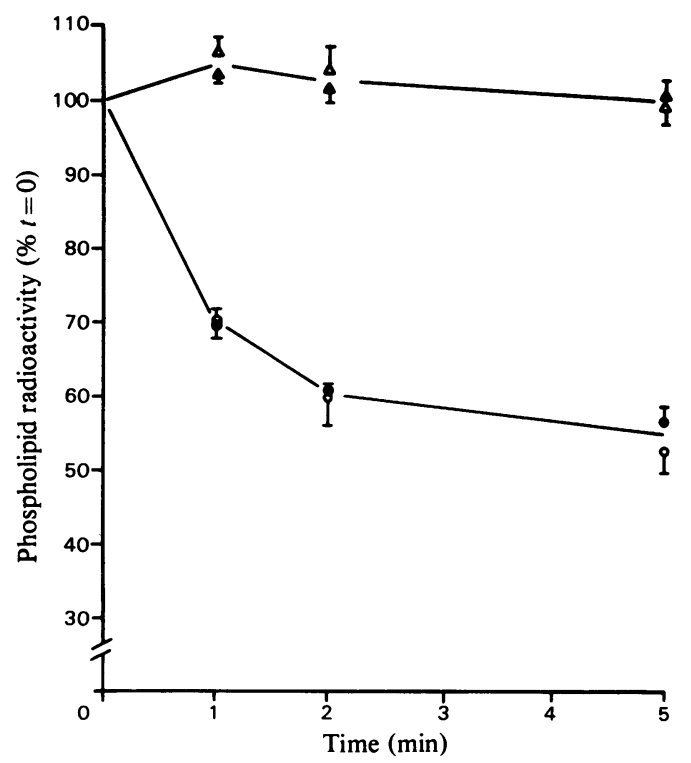

Fig. 2. Effect of $0.1 \mathrm{mM}$-methacholine on ${ }^{32} \mathrm{P}$-labelled polyphosphoinositides

Cells were pre-incubated with $\left[{ }^{32} \mathrm{P}\right] \mathrm{P}_{\mathrm{i}}$ for $30(\mathbf{0}, \Delta)$ or $60(0, \Delta) \mathrm{min}$, and samples were taken just before $(t=0)$, and 1,2 and $5 \mathrm{~min}$ after addition of $0.1 \mathrm{mM}$ methacholine. and $O, \operatorname{PtdIns}(4,5) P_{2} ; \Delta$ and $\Delta$, PtdIns4P. Results are means \pm S.E.M. for four experiments. propranolol to assure activation of only the $\alpha$ adrenoceptor pathway. Of the three agents (methacoline, Substance P, adrenaline with propranolol), methacholine caused the greatest effect. The temporal patterns of radioactivity loss due to methacholine and adrenaline were similar. The pattern for Substance $P$ differed, however, the effect being equal to that for methacholine for the first minute, but the labelled PtdIns $(4,5) P_{2}$ subsequently rose such that the net change was, at 5-10 min, more similar to the less efficacious adrenaline. None of the three agonists had significant effects on PtdIns $4 P$ radioactivity (results not shown).

The $\beta$-adrenoceptor catecholamine, isoprenaline $(10 \mu \mathrm{M})$, and the $\mathrm{Ca}^{2+}$ ionophore, ionomycin $(2.67 \mu \mathrm{M})$, were tested for effects on the polyphosphoinositides. Neither compound significantly affected radioactive PtdIns(4,5) $P_{2}$ or PtdIns4 $P$ (results not shown; less than $5 \%$ change), whereas in two concurrent experiments, methacholine caused a decrease similar to the preceding experiments.

The rapidity of the effect of methacholine on PtdIns $(4,5) P_{2}$ was examined in experiments shown in Fig. 4. Analysis of variance showed that PtdIns-

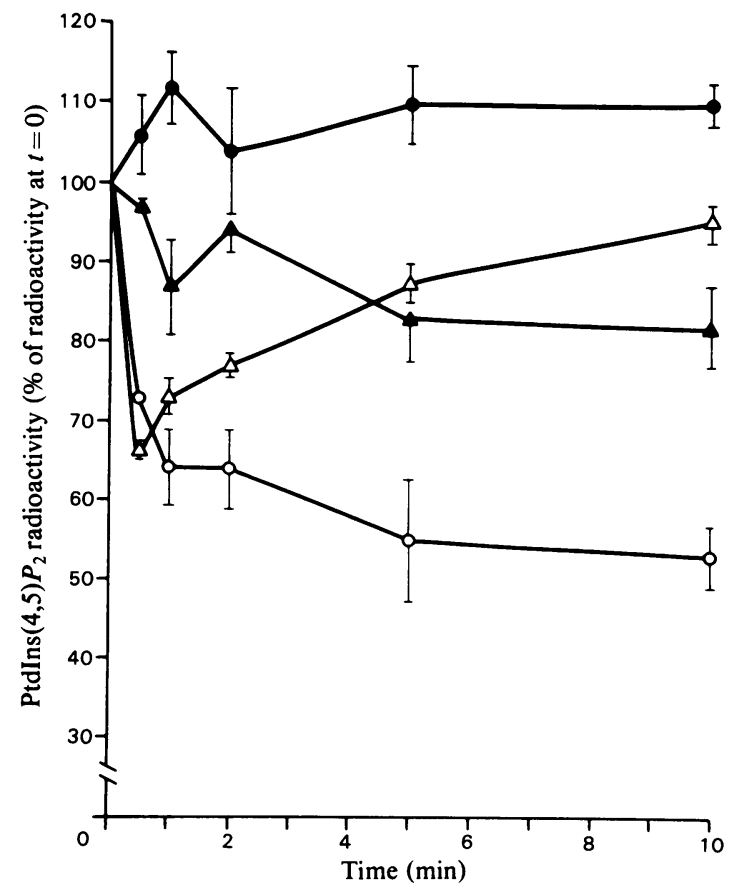

Fig. 3. Radioactivity in PtdIns $(4,5) P_{2}$ (as a percentage of the value at $t=0$ ) as affected by various agents

, Control (no agonist); $0,0.1 \mathrm{~mm}$-methacholine: $\Delta, \quad 0.1 \mathrm{mM}$-adrenaline $+10 \mu \mathrm{M}$-propranolol; $\Delta$, $0.1 \mu \mathrm{M}$-Substance P. Results are means \pm S.E.M. for three experiments. 


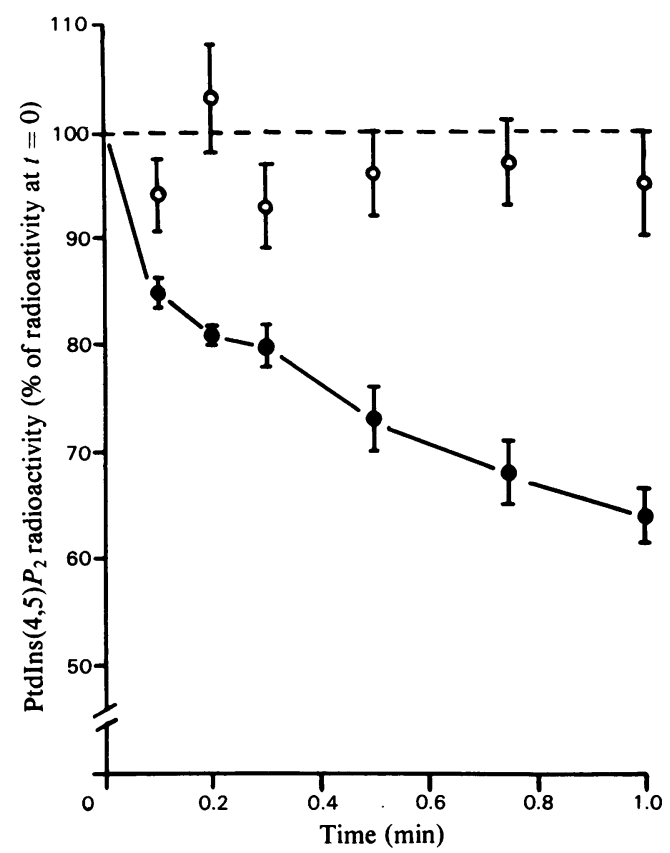

Fig. 4. Time course of PtdIns $(4,5) P_{2}$ breakdown caused by $0.1 \mathrm{mM}$-methacholine

Samples were taken every $6 \mathrm{~s}$ after addition of $0.1 \mathrm{mM}$-methacholine and data were expressed as percentages of radioactivity before agonist addition. $\mathrm{O}$, Control (no agonist);, $0.1 \mathrm{~mm}$-methacholine. Results are means \pm S.E.M. of three $(O)$ or four $(\bullet)$ determinations.

$(4,5) P_{2}$ radioactivity differed from the concurrently run controls at all times, including the earliest sample taken $6 \mathrm{~s}$ after the addition of methacholine.

The relationship of $\mathrm{Ca}^{2+}$-mobilization to the reeeptor-mediated effects of labelled $\operatorname{PtdIns}(4,5) P_{2}$ was examined in experiments shown in Fig. 5. In these experiments, methacholine was added to the cells at $t=0$, atropine, to block the effects of methacholine at $10 \mathrm{~min}$, and substance $P$ at $20 \mathrm{~min}$. Paired experiments were carried out in the presence or absence of external $\mathrm{Ca}^{2+}$. For the low- $\mathrm{Ca}^{2+}$ experiments, cells were pre-incubated in normal Ringer for $55 \mathrm{~min}$, at which time $(5 \mathrm{~min}$ before methacholine addition) 2 mM-EGTA was added, which effectively decreases external $\left[\mathrm{Ca}^{2+}\right]$ to less than $1 \mu \mathrm{M}$. Analysis of variance revealed no significant differences in the pattern of this experiment when $\mathrm{Ca}^{2+}$ was absent compared with the pattern in its presence.

The data on PtdIns $4 P$ radioactivity from these same experiments are shown in Fig. 6 (note the expanded scale). As before, only minor (and insignificant) changes were observed when agonists were

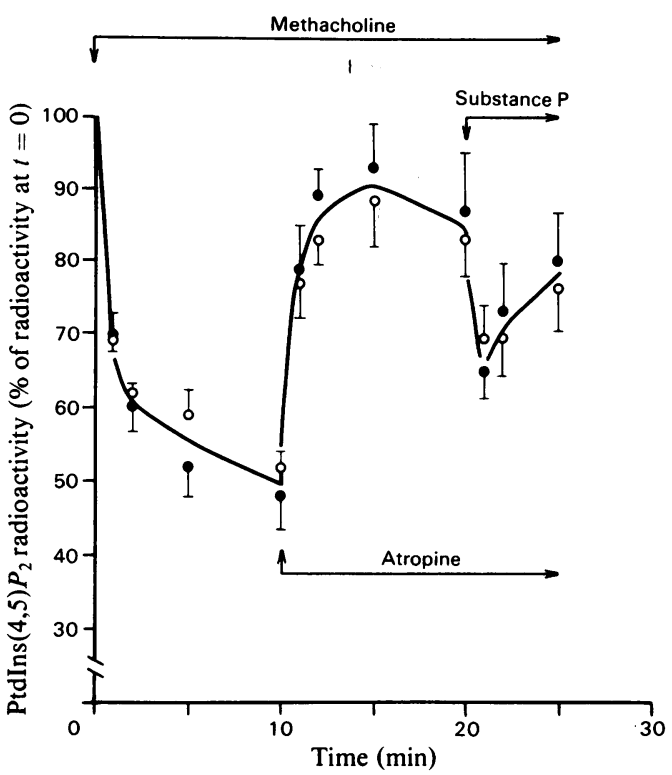

Fig. 5. Effect of $\mathrm{Ca}^{2+}$ omission on changes in PtdIns$(4,5) P_{2}$ levels induced by agonists and antagonists Methacholine $(0.1 \mathrm{mM})$, atropine $(10 \mu \mathrm{M})$ and Substance $P(0.1 \mu \mathrm{M})$ were added as indicated. $\bullet$. Experiments carried out in normal Ringer: $O$, $2 \mathrm{~mm}$-EGTA was added $5 \mathrm{~min}$ before the addition of agonist. Results are means \pm S.E.M. for four experiments.

applied, but when atropin was applied after methacholine, a $20-30 \%$ increase in PtdIns4P labelling was observed that was statistically significant and roughly paralleled the rise in radioactive PtdIns$(4,5) P_{2}$ in Fig. 5.

To obtain an approximation of the $\operatorname{PtdIns}(4,5) P_{2}$ content of the parotid, a rat was injected subcutaneously with $100 \mu \mathrm{Ci}$ of $\left[{ }^{3} \mathrm{H}\right]$ inositol. After $18 \mathrm{~h}$, the animal was anaesthetized, the glands were removed, each gland was cut in half and each of the four pieces rapidly homogenized in cold chloroform/ methanol $(1: 2, \mathrm{v} / \mathrm{v})$. The phospholipids were extracted as before and chromatographed on plates with $\left[{ }^{32} \mathrm{P}\right] \mathrm{P}_{\mathrm{i}}$-labelled specimens in parallel lanes. Autoradiographic localization of $\operatorname{PtdIns}(4,5) P_{2}$ in the parallel lanes were used to predict the location of the ${ }^{3} \mathrm{H}$-labelled material. From the replications of the analyses from this single animal, the $\left[\operatorname{PtdIns}(4,5) P_{2}\right] /[$ PtdIns $]$ ratio was estimated to be $0.053 \pm 0.010$. From prior estimates of parotid PtdIns content $(12 \mathrm{nmol} / \mathrm{mg}$ of protein; Weiss \& Putney, 1981), an estimate of PtdIns $(4,5) P_{2}$ content of about $0.6 \mathrm{nmol} / \mathrm{mg}$ of protein is obtained, although this must be regarded as a rather approximate value. 


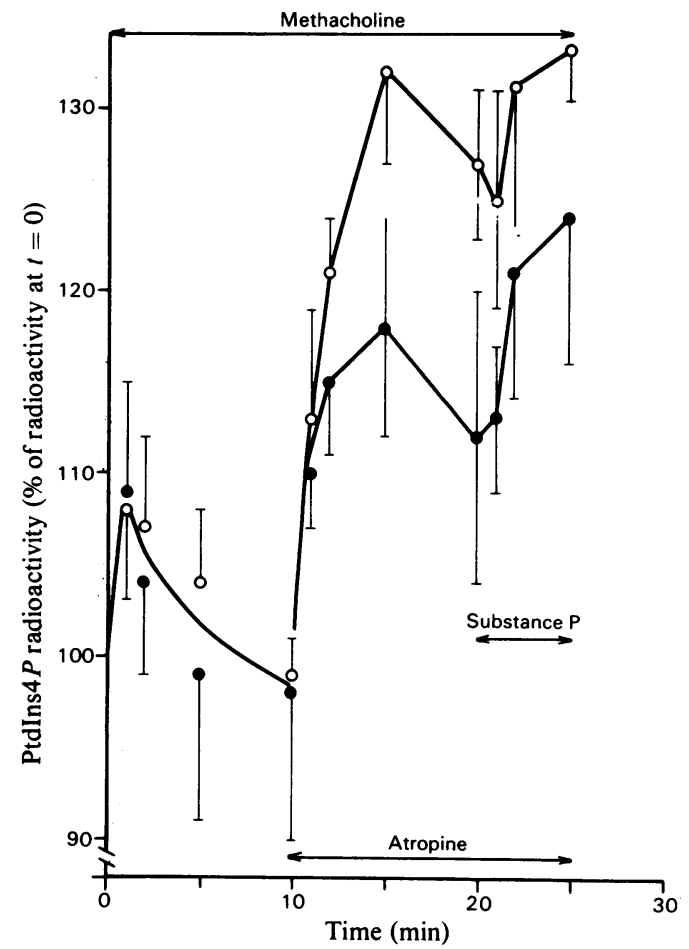

Fig. 6. Radioactivity in PtdIns4P from the same experiments as shown in Fig. 5

For explanation of the symbols, see the legend to Fig. 5.

\section{Discussion}

The rat parotid gland can be activated by any of four known receptor pathways: $\beta$-adrenergic, $\alpha$-adrenergic, muscarinic (cholinergic) and substance P (Schramm \& Selinger, 1975; Putney, 1978). The $\beta$-adrenoceptor pathway primarily regulates protein secretion utilizing cyclic AMP as second messenger. The other three pathways (muscarinic, $\alpha$-adrenergic, Substance $P$ ) primarily regulate univalent ion fluxes. which may be involved in secretion of water and electrolytes; apparently $\mathrm{Ca}^{2+}$ serves as second messenger for these effects (Putney, 1978). Further, the evidence suggests that these three receptors in the parotid (and probably elsewhere) mobilize $\mathrm{Ca}^{2+}$ by two mechanisms: an enhancement of $\mathrm{Ca}^{2+}$ influx (increased membrane permeability to $\mathrm{Ca}^{2+}$ ) and release of bound or sequestered $\mathrm{Ca}^{2+}$ from some cellular store (Putney et al., 1981). Indirect evidence suggests that the releasable pool of cellular $\mathrm{Ca}^{2+}$ may reside in the plasma membrane (Poggioli \& Putney, 1982).

The data obtained in this investigation suggest that breakdown of a specific pool of PtdIns $(4,5) P_{2}$ could play a role in the mechanism by which receptor activation effects $\mathrm{Ca}^{2+}$-mobilization. The arguments are similar to those developed originally by Michell (1975, 1979), suggesting such a role for PtdIns breakdown. The data in Fig. 3 show that this reaction is activated by receptors involved in $\mathrm{Ca}^{2+}$ mobilization. However, the effect cannot be provoked through the $\beta$-adrenergic receptor, which acts through cyclic AMP. Despite this association with the $\mathrm{Ca}^{2+}$ pathway, the data also clearly show that PtdIns $(4,5) P_{2}$ loss is not a consequence of $\mathrm{Ca}^{2+}$ mobilization. For example, ionomycin, a $\mathrm{Ca}^{2+}$-ionophore, failed to stimulate $\operatorname{PtdIns}(4,5) P_{2}$ breakdown. Previous studies have shown that this concentration of ionomycin $(2.67 \mu \mathrm{M})$ under these experimental conditions provokes $\mathrm{Ca}^{2+}$-mobilization and $\mathrm{Ca}^{2+}$ mediated responses of a magnitude similar to those obtained with muscarinic agonists (Poggioli et al., 1982).

The addition to the cell suspension of EGTA in concentrations sufficient to decrease external $\left[\mathrm{Ca}^{2+}\right]$ to less than $1 \mu \mathrm{M}$ failed to affect the PtdIns $(4,5) P_{2}$ breakdown response to methacholine (Fig. 5). However, the possibility exists that receptor-mediated intracellular $\mathrm{Ca}^{2+}$ release known to occur in $\mathrm{Ca}^{2+}$ deficient media (Haddas et al., 1979) could be acting as catalyst for the PtdIns(4,5) $P_{2}$ effect. This possibility is effectively ruled out by the ability of Substance $P$ to cause PtdIns(4,5) $P_{2}$ breakdown in the $\mathrm{Ca}^{2+}$-deficient medium. It has previously been shown that this experimental sequence, i.e.. muscarinic agonist followed by muscarinic antagonist followed by Substance $P$, results in a failure of $\mathrm{Ca}^{2+}$ release by Substance $P$ due to the prior depletion of the relevant $\mathrm{Ca}^{2+}$ pool by the cholinergic agonist (Putney, 1977; Haddas et al., 1979; Poggioli \& Putney, 1982). Thus in the experiments of Fig. 5 in $\mathrm{Ca}^{2+}$-deficient medium, Substance $\mathbf{P}$ causes $\operatorname{PtdIns}(4,5) P_{2}$ breakdown in the absence of either $\mathrm{Ca}^{2+}$-influx or $\mathrm{Ca}^{2+}$-release. Taken with the failure of ionomycin to cause $\operatorname{PtdIns}(4,5) P_{2}$ breakdown, this finding clearly establishes receptor-activated PtdIns $(4,5) P_{2}$ breakdown as an event that is not mediated by $\mathrm{Ca}^{2+}$-mobilization. It is noteworthy, however, that these results do not rule out a possible requirement for tightly bound $\mathrm{Ca}^{2+}$ for one or more of the enzymes involved in the response. Rather, the point is that the loss of $\operatorname{PtdIns}(4,5) P_{2}$ that comes about as a consequence of receptor activation does not result from the alterations in cellular $\left[\mathrm{Ca}^{2+}\right]$ that agonists invoke.

Following Michell's logic as originally applied to PtdIns turnover (Michell, 1975), this would suggest that PtdIns $(4,5) P_{2}$ breakdown may be an early event following receptor activation and one preceding $\mathrm{Ca}^{2+}$-mobilization. Conducive to this idea is the demonstrated rapidity of $\operatorname{PtdIns}(4,5) P_{2}$ breakdown (Fig. 4). Also, the time course of PtdIns $(4,5) P_{2}$ 
breakdown, being essentially complete in $2 \mathrm{~min}$, is consistent with the time course of net ${ }^{45} \mathrm{Ca}^{2+}$ release (Poggioli \& Putney, 1982). As the polyphosphoinositides are known to bind $\mathrm{Ca}^{2+}$ well (Dawson \& Hauser, 1979), it is tempting to speculate that $\mathrm{Ca}^{2+}$. release could arise directly from the breakdown of a $\operatorname{PtdIns}(4,5) P_{2}-\mathrm{Ca}^{2+}$ complex. Consistent with this idea is the generally held view that the polyphosphoinositides may be localized in the plasma membrane (Michell, 1975), which is believed to be the site of receptor-activated $\mathrm{Ca}^{2+}$-release (Poggioli \& Putney, 1982). Studies on the subcellular distribution of the polyphosphoinositides in the parotid gland have not been carried out, however. The roughly estimated PtdIns $(4,5) P_{2}$ content of $0.6 \mathrm{nmol} / \mathrm{mg}$ of protein would suggest a breakdown in the range of about $0.3 \mathrm{nmol} / \mathrm{mg}$ of protein if all of the cellular PtdIns$(4,5) P_{2}$ were labelled equally with $\left[{ }^{32} \mathrm{P}\right] \mathrm{P}_{\mathrm{i}}$. Estimates of the quantity of $\mathrm{Ca}^{2+}$ released after receptor activation are in the range $0.2-0.5 \mathrm{nmol} / \mathrm{mg}$ of protein (calculated from data in Poggioli \& Putney, 1982). Although there is not sufficient data as yet for rigorous quantitative comparison of these parameters, this treatment does show that one estimate of the small quantity of PtdIns $(4,5) P_{2}$ lost may at least be in the range anticipated for $\mathrm{Ca}^{2+}$ release.

It is not possible from these data to suggest a specific pathway for loss of PtdIns $(4,5) P_{2}$. The term breakdown seems tentatively justified only in the absence of known synthetic pathways utilizing PtdIns $(4,5) P_{2}$. Reversal of, or decrease in, synthesis of PtdIns $(4,5) P_{2}$, for example by stimulation of a PtdIns $(4,5) P_{2}$ phosphomonoesterase or inhibition of PtdIns4P kinase seems unlikely (but not disproven) since PtdIns $4 P$ radioactivity is unaltered. This also argues against a secondary effect on PtdIns $(4,5) P_{2}$ after PtdIns breakdown, i.e., by decreasing one of the substrates for PtdIns $(4,5) P_{2}$ synthesis. It also effectively rules out effects secondary to changes in labelled ATP. In fact, since PtdIns4P is the only known intermediate linking PtdIns and $\operatorname{PtdIns}(4,5) P_{2}$, there is no readily apparent connection between the observed receptor-mediated breakdown of these two inositides, and we must tentatively consider the possibility that they represent distinct pathways. Since resynthesis of $\operatorname{PtdIns}(4,5) P_{2}$ after atropine treatment (Fig. 5) was associated with a small increase in PtdIns4P, the route of synthesis could involve the previously described sequential phosphorylation of PtdIns (Michell, 1975). Other tissues have been shown to contain $\operatorname{PtdIns}(4,5) P_{2}$ phosphodiesterase activity, which could be the pathway involved (Akhtar \& Abdel-Latif, 1980; Downes \& Michell, 1981). Until breakdown products are identified, however, other mechanisms remain as possibilities. Hopefully, continued research in this area will more clearly define these pathways, and extend our understanding of the roles of phosphoinositide metabolism in mechanisms of $\mathrm{Ca}^{2+}$. mobilization.

This study was supported by a grant (no. DE-05764) from the N.I.H.

\section{References}

Abdel-Latif, A. A., Akhtar, R. A. \& Hawthorne, J. N. (1977) Biochem. J. 162, 61-73

Akhtar, R. A. \& Abdel-Latif, A. A. (1978) J. Pharmacol. Exp. Ther. 204, 655-668

Akhtar, R. A. \& Abdel-Latif, A. A. (1980) Biochem. J. 192, 783-791

Berridge, M. J. (1980) Trends Pharmacol. Sci. 1, 419424

Bligh, E. G. \& Dyer, W. J. (1959) Can. J. Biochem. Physiol. 37, 911-917

Cockroft, S., Bennet, J. P. \& Gomperts. B. D. (1980a) FEBS Lett. 110, 115-118

Cockroft, S., Bennet, J. P. \& Gomperts, B. D. (1980b) Nature (London) 288, 275-277

Dawson, R. M. C. \& Hauser, H. (1979) in Calcium and Cellular Function (Cuthbert, A. W., ed.), pp. 17-41, Macmillan, London

Downes, C. P. \& Michell, R. H. (1981) Biochem. J. 198. $133-140$

Fisher, S. K. \& Agranoff, B. W. (1980) J. Neurochem. 34. 1231-1240

Haddas, R. A., Landis, C. A. \& Putney, J. W., Jr. (1979) J. Physiol. (London) 291, 457-465

Jones, L. M. \& Michell, R. H. (1974) Biochem. J. 142. 583-590

Kirk, C. J., Creba, J. A., Downes, C. P. \& Michell, R. H. (1981) Biochem. Soc. Trans. 9, 377-379

Lapetina, E. G. \& Michell, R. H. (1972) Biochem. J. 126, 1141-1147

Michell, R. H. (1975) Biochim. Biophys. Acta 415, 81-147

Michell, R. H. (1979) Trends Biochem. Sci. 4. 128-131

Poggioli, J. \& Putney, J. W., Jr. (1982) Pflügers Arch. 392, 239-243

Poggioli, J., Leslie, B. A., McKinney, J. S., Weiss, S. J. \& Putney, J. W., Jr. (1982) J. Pharmacol. Exp. Ther. 221, 247-253

Putney, J. W., Jr. (1977) J. Physiol. (London) 268. 139149

Putney, J. W., Jr. (1978) Pharmacol. Rev. 30, 209-245

Putney, J. W., Jr. (1981) Life Sci. 29, 1183-1194

Putney, J. W., Jr., Van DeWalle, C. M. \& Leslie, B. A. (1978) Mol. Pharmacol. 14, 1046-1053

Putney, J. W., Jr., Poggioli, J. \& Weiss, S. J. (1981) Philos. Trans. R. Soc. London Ser. B 296, 37-45

Schacht, J. (1978) J. Lipid Res. 19, 1063-1067

Schramm, M. \& Selinger, Z. (1975) J. Cyclic Nucleotide Res. 1, 181-192

Weiss, S. J. \& Putney, J. W., Jr. (1981) Biochem. J. 194. 463-368 